\title{
Formação inicial de professores que ensinam matemática e o sistema de numeração decimal
}

Initial training of teachers who teach mathematics and the decimal numbering system

Raquel Soares do Rêgo Ferreira (iD) https://orcid.org/0000-0002-6718-1905

Universidade Federal do Pará

e-mail - raquellrego@gmail.com

Renato Borges Guerra (iD https://orcid.org/0000-0002-9228-2337

Universidade Federal do Pará

e-mail - rgufpa@gmail.com

\section{Resumo}

Este artigo apresenta parte de uma pesquisa doutoral em andamento que usa o suporte teórico e metodológico da Teoria Antropológica do Didático para questionar e responder se o sistema de numeração decimal é um conhecimento naturalizado no seio das práticas de um grupo de professores em formação inicial para os anos iniciais do ensino fundamental. O interesse nessa questão decorre da naturalização dos números decimais, uma vez que há dificuldade no seu ensino e aprendizagem como objetos estruturados segundo o sistema de numeração posicional. A metodologia usada, em consonância com os recursos teóricos, foi o desenvolvimento de um percurso de estudo e pesquisa, a partir de uma situação não rotineira entre as práticas docentes escolares das séries iniciais, com ajuda de um diretor de estudo tomado entre os autores dessa pesquisa. Os resultados encontrados ratificam a hipótese inicial de naturalização desse sistema de numeração pelos professores em formação inicial que demonstram e ratificam a potência da metodologia empregada nessa pesquisa como um dispositivo didático de ensino, inclusive para a formação docente.

Palavras-chave: Formação inicial de professor. Sistema de Numeração Decimal (SND). Teoria Antropológica do Didático (TAD). Percurso de Estudo e Pesquisa (PEP).

\section{Abstract}

This article presents part of an ongoing doctoral research that uses the theoretical and methodological support of the Anthropological Theory of Didactics to question and answer whether the decimal numbering system is a naturalized knowledge within the practices of a group of teachers in initial training for students. initial years 
of middle school. The interest in this issue arises from the naturalization of decimals numbers, since there are difficulties in teaching and learning as objects structured according to the positional numbering system. The methodology used, in line with the theoretical resources, was the development of a study and research path, based on a non-routine situation among school teaching practices in the initial grades, with the help of a study director taken among the authors of this research. The results found confirm the initial hypothesis of naturalization of this numbering system by teachers in initial training and demonstrate and ratify the power of the methodology employed in this research as a teaching device, including for teacher training.

Keywords: Initial teacher training. Decimal numbering system. Anthropological Theory of Didactics (TAD). Course of study and research (CSR).

\section{Introdução}

Diferentes sistemas de numerações estão disponibilizados pela história do desenvolvimento do conhecimento social de diferentes civilizações e, entre eles, encontramos os sistemas egípcio, grego, romano, maia, e o sistema de origem hindu-arábica que guarda similitudes com os anteriores. Este se constitui como nosso objeto de interesse por ser o sistema de numeração usado nos dias atuais em diferentes práticas de nossa sociedade, inclusive para o ensino e aprendizagem nas escolas do ensino fundamental. Esse sistema é conhecido como Sistema de Numeração Decimal (SND).

Segundo Ifrah (1985) esse sistema teria sido trazido pela civilização Árabe até a Europa, em meados do século VII, de onde foi difundido para as demais civilizações, tornando-se dominante hoje no mundo. Talvez por isso seu ensino tenha se tornado necessário ou indispensável nas escolas, inicialmente, para atender aos ofícios de diferentes práticas sociais dentre as atividades humanas que, mais tarde, foram incluídas nas escolas de saberes fundamentais.

No entanto, o ensino sobre o SND tem sido questionado por diferentes pesquisadores, considerando aspectos distintos e associados a dois outros estreitamente relacionados. O primeiro, refere-se à baixa efetividade para o ensino das organizações de conteúdos presentes nos livros didáticos, considerando o fracasso escolar proporcionado por essas organizações no ensino, como apontam Terigi e Wolman (2007) e Itzcovich (2008), por exemplo, o segundo, à insuficiente formação matemática dos professores que atuam nas séries iniciais, apontada, por exemplo, por Ripoll, Rangel e Giraldo (2016) e Cenci, Becker e Mackedanz (2015) e Sadovsky (2010).

Os estudos de Cenci, Becker e Mackedanz (2015) tratam do debate acadêmico sobre a formação de professores para séries iniciais frente ao ensino do SND envolvendo aproximadamente duzentos trabalhos desenvolvidos no período de 2008 a 2015. Como resultado, apontam diferentes aspectos sobre o ensino da matemática, entre eles, o do predominante uso da epistemologia genética nas pesquisas com foco sobre metodologias de ensino.

Em relação a essa linha de pensamento, Cenci, Becker e Mackedanz (2015) destacam que Garcia (2006) e Bathelt (2000) apontam a necessidade de enfrentar o desafio de desenvolver conhecimentos específicos para ensinar matemática que "não são definidos apenas pelos conteúdos, mas também pela prática docente dos 
professores para que possam ser aprendidos pelos alunos" (CENCl; BECKER; MACKEDANZ, 2015, p. 33).

Seguindo, e recorrendo a Carvalho (2004), afirma que os conteúdos matemáticos aprendidos nos cursos de formação de professores para as séries iniciais pouco contribuem para as práticas pedagógicas, pois os acadêmicos carregariam, desde a educação básica, uma didática de reprodução de modelos. Nessa linha, concluem que a insegurança presente nos professores em formação, relativo ao ensino da matemática, encaminham o desafio de um ensino matemático que desenvolva um conhecimento que lhes permitam "assumir com segurança os conteúdos a serem ministrados e de tal modo que sejam considerados satisfatórios". (CENCl; BECKER; MACKEDANZ, 2015, p. 33).

Cenci, Becker e Mackedanz (ibidem) destacam que é necessária a integração de conhecimentos de práticas docentes como parte integrante dos conhecimentos matemáticos que permitam aos professores fazerem com que os alunos aprendam de modo satisfatório os conhecimentos matemáticos, em particular, para o ensino e a aprendizagem do SND.

É sobre a problemática de formação de professores, especificamente, formação do professor em relação a um dado conhecimento específico, nesse caso, sobre o sistema de numeração decimal, que detemos nossos esforços de investigação em busca de responder ao questionamento, o qual apresentamos a seguir.

\section{A questão de investigação}

Como destacamos, é necessário mais que o conhecimento do conteúdo matemático para que o professor possa organizar e programar suas práticas docentes, já que existem conhecimentos que deveriam ser objetos de ensino na formação inicial desses professores, sendo assim necessários para a árdua tarefa de replanejar o ensino, de modo que os alunos aprendam como desejado pelas instituições avaliadoras, inclusive a própria escola.

Dessa forma, as práticas docentes relativas ao conhecimento ensinado que produzem bons resultados de aprendizagens deveriam se tornar objetos de investigação. Essa linha de investigação foi inaugurada pelo programa epistemológico da didática da matemática que marca a integração da atividade matemática na atividade pedagógica, ou seja, passa a considerar que o conhecimento matemático para ser ensinado precisa sofrer transformações que permitam ser ensinável e, em consequência, aprendido. De outro modo, o conhecimento matemático passa a ser questionado para o ensino.

A integração do matemático ao pedagógico foi proposto incialmente por Schulman (1986) quando clama que, para o ensino não basta o conhecimento do conteúdo matemático, "considerado classicamente como o conteúdo de ensino da matemática, transparente, inquestionável e independente da forma de ensinar" (BOSCH; GASCÓN, 2001, p. 10, tradução nossa). Para isso seria necessário, senão indispensável, o conhecimento pedagógico do conteúdo, que além do conhecimento matemático, incluiria

Que os conhecimentos do professor relativos à aprendizagem dos alunos sobre um conteúdo específico e, em particular, o conhecimento que tem o professor sobre as dificuldades típicas dos alunos em cada tópico 
matemático concreto e do modo de prevê-las e remediá-las" $(\mathrm{BOSCH}$; GASCÓN, 2001, p. 13, tradução nossa).

Em que pese a dificuldade de delimitar a noção de conhecimento pedagógico de conteúdo, como destaca Schoenfeld (2000), de modo que nos permita reconhecêlos, acessá-los e organizá-los, Ripoll, Rangel e Giraldo (2016) encaminha uma possível resposta à problemática de formação de professores em relação ao SND. Para isso, interpretam da noção de conhecimento pedagógico de conteúdo a partir dos trabalhos de Klein $(2009,2010,2011)$, os quais propõem a fundamentação das organizações de conteúdo matemático escolar por meio da matemática acadêmica como condição necessária para vencer a insegurança e a difícil tarefa docente de replanejamento do ensino para, em seguida, interpretá-los a partir de Schulman (1986). Nesse sentido, o conhecimento pedagógico do conteúdo estaria assegurado pelo suposto poder epistemológico que a matemática acadêmica goza e com isso encaminharia a legitimidade do conhecimento pedagógico do conteúdo a ser produzido pelo professor quando necessário.

Entretanto, Ripoll, Rangel e Giraldo (2016) concentra em seu trabalho a ênfase no conteúdo matemático que, como tal, independe das práticas de ensino e aprendizagem sobre o SND, em particular, das que envolvem a quantificação de materiais concretos, considerando que elas são aplicações do conhecimento do conteúdo matemático. Assim, por exemplo, a contagem de um aglomerado de cadeiras, será considerada uma aplicação da noção matemática de números naturais, mesmo que a noção deles tenha emergido muito tempo depois dos numerais decimais, inclusive como abstração destes.

Em vista disso, Ripoll, Rangel e Giraldo (2016), ignoram a epistemologia histórica do SND como parte do conteúdo a ser ensinado e consideram apenas elementos históricos da matemática sobre o SND como recurso pedagógico de ajuda ao ensino e aprendizagem para, em conveniente consonância com o inquestionável conhecimento matemático, prover uma suposta condição necessária para o replanejamento de práticas docentes sobre o SND, em particular, para o momento só do professor que antecede a sala de aula, em que ele escreve sua aula em suposto diálogo com seus alunos hipotéticos. No entanto, não apontam como fazer esses procedimentos que se consolidem em uma organização de conhecimentos para o ensino do SND de modo que os professores e alunos aprendam.

No contexto do programa epistemológico da didática da matemática, a problemática de formação do professor em relação aos conhecimentos a serem ensinados, ganha diferentes encaminhamentos em consonâncias entre si, como a teoria das situações didáticas de Brousseau (1998) e a teoria da Transposição didática de Chevallard (1985) que mais tarde foi fundamentada pela Teoria Antropológica do Didático (CHEVALLARD, 1999), simplesmente, TAD. A linha teórica da TAD encaminhou vasto campo de investigação sobre a formação de professores de matemática (BOSCH; CHEVALLARD; CIRADE; LADAGE, 2019) em que é incluído, de modo indispensável, o estudo e a produção de organizações didáticas com conteúdos matemáticos para o ensino.

Nesse contexto teórico, ganha relevância a gênese histórica e epistemológica do conteúdo matemático por encaminhar as condições que conformam a razão e o sentido de produção e da difusão do conhecimento matemático a ser ensinado e que são necessários para ajudar a revelar outros conhecimentos, não raros, mas 
nebulosos que foram, e podem continuar sendo, indispensáveis para o funcionamento das práticas de ensino relativos aos conhecimentos ensinados.

Além disso, outros conhecimentos da atualidade, inclusive das práticas docentes, recorridos nas reconstruções dos conhecimentos ensinados, condicionam, às vezes de modo restritivo, o ensino e a aprendizagem de um dado conhecimento específico para uma dada classe no interior de uma dada instituição escolar em um dado tempo.

Assim, há a necessidade de questionar as organizações didáticas relativas ao SND como condição inicial para fazer revelar possíveis problemáticas relativas ao ensino e aprendizagem. Questionar as organizações didáticas quer dizer questionar o SND enquanto produto de uma atividade de transposição didática, aqui entendida como o trabalho de transformações e adaptações do SND para ser ensinado, tendo em conta suas relações com os outros conhecimentos matemáticos e não matemáticos, inclusive não disciplinares, que podem contribuir para uma organização didática que atendam às necessidades do ensino e, como consequência, da aprendizagem.

Sob esse pensar, as práticas docentes em sala de aula se constituem em uma recriação dos conteúdos matemáticos para situações de ensino de modo a atender uma intencionalidade didática, mas sem perder de vista que essa recriação é condicionada pela civilização, sociedade, escola e a pedagogia, além da própria matemática, em que os conhecimentos estudados se encontram inseridos.

Desse modo, precisaríamos questionar quais são os supostos conteúdos matemáticos pertinentes para o ensino dos numerais decimais, considerando que são dotados de uma gênese histórica que antecede a própria gênese dos conjuntos de números matemáticos. Além disso, os números decimais foram, e continuam sendo, objetos presentes em diferentes práticas sociais de diferentes atividades humanas antes de se tornarem um conhecimento matemático escolar.

Poderíamos supor, por exemplo, que há uma naturalização dos numerais decimais que impedem sua compreensão na escola como produtos de um algoritmo ou prática regrada que, como tal, é dotado de uma estrutura que pode ser vista como abstração, senão descrição, de um processo prático de quantificação de grandezas discretas, denominado de sistema de numeração decimal ou, simplesmente, SND. Que em superior abstração, leva ao encontro do sistema de numeração posicional ou, simplesmente, SNP.

As investigações de Terigi e Wolman (2007), Itzcovich (2008) e Sadovsky (2010), tomam o questionamento das práticas matemáticas escolares sobre o SND como provedora de formação de professores relativo a esses conhecimentos e destacam que a presença rotineira dos numerais decimais em diferentes práticas sociais na sociedade tem implicações sobre o seu ensino.

Especificamente, nessas práticas seria comum a presença de numerais decimais em sua forma falada, que levam a serem "declamados" pelas crianças e professores na escola, e da numeração escrita que se aprende por meio de uma lógica prática, ou seja, como um habitus ${ }^{1}$ que se aprende por imitação, vendo e fazendo o que se viu fazer (BOURDIEU, 2004).

\footnotetext{
${ }^{1} \mathrm{O}$ habitus como social inscrito no corpo, no indivíduo biológico, permite produzir uma infinidade de atos de jogo que estão inscritos no jogo em estado de possibilidades e de exigências objetivas; as coações e exigências do jogo, ainda que não estejam reunidas num código de regras, impõem-se àqueles e somente àqueles que,
} 
Essa compreensão de naturalização dos números decimais compartilhada por Terigi e Wolman (2007), Itzcovich (2008) Sadovsky (2010), como podemos depreender, também é apontada por Ripoll, Rangel e Giraldo (2016) quando assim afirmam:

\begin{abstract}
Realizar esses procedimentos em outras bases tira-nos da "zona de conforto" que a base 10 proporciona, e nos força a pensar nas justificativas para cada um dos passos que executamos automaticamente cujas validades são tomadas como certas. Esse exercício pode ajudar o professor a entender com mais clareza procedimentos que ensina usualmente aos alunos. (RIPOLL; RANGEL; GIRALDO, 2016, p. 32).
\end{abstract}

Parece-nos que a afirmativa aponta sobre o fato de a automaticidade dos passos de construção dos numerais ter validade na cultura da prática de numeração e, portanto, que o SND é suficientemente naturalizado e, como tal, goza da transparência para o sucesso de realização dessa prática.

Nesse sentido, o extrato de texto remete à afirmação de que a capacidade do aluno, inclusive do professor, em executar corretamente o algoritmo que atribui denominação aos dígitos dos numerais em acordo com a posição que ocupam em numeral decimal, não asseguraria por si só a compreensão adequada da estrutura posicional do SND.

De outro modo, os numerais decimais são objetos do conhecimento social que são acessados pelos agentes sociais de modo quase transparente, como um conhecimento paramatemático (CHEVALLARD, 2005) que no ensino são conhecimentos utilizados de modo inquestionável e indispensável, mas que jamais são objetivamente ensinados. São conhecimentos institucionalizados por nossa civilização, cultura e sociedade e que por esse motivo podem impedir que a estrutura dos numerais decimais não seja, ou não se faça visível na escola.

Terigi e Wolman (2007) que investigaram como o ensino usual do sistema de numeração pode contribuir para a produção de fracassos na escola, consideram como uma condição também compartilhada por Itzcovich (2008), a necessária desnaturalização do conhecimento adulto das regras que regem o SND.

Sadovsky (2010) por sua vez, destaca que para vencer essa naturalização, uma condição imprescindível "é revisar a matemática que vive na escola, interrogá-la, analisá-la de modo a conceber outros cenários (de ensino)" (Ibidem, p.13). Entendemos que, em particular, sobre o SND, um cenário possível seria investigálo a partir de quantificações por meio de agrupamentos sucessivos, não decimais, tal qual sugere Ripoll, Rangel e Giraldo (2016).

As investigações aqui citadas encaminham por assertivas a naturalização dos números decimais, inclusive como obstáculo ou dificuldade ao aprendizado da estrutura desses numerais. Entretanto, considerando o pressuposto teórico da TAD de que todo conhecimento é situado e sujeito a variações impostas pelas condições que conformam as situações, tomamos a naturalização em hipótese e, portanto, compreendemos a necessidade de ela ser validada ou não perante um contexto concreto de formação de professores de series iniciais relativo ao SND. Nesse contexto, a condição hipotética foi considerada por meio do seguinte

por terem o sentido do jogo, isto é, o senso da necessidade imanente do jogo, estão preparados para percebêlas e realizá-las. (BOURDIEU, 2004, p.82) 
questionamento $Q$ : Os professores em formação inicial conhecem ou não o SND como um SNP?

A resposta a esse questionamento torna-se o propósito da presente investigação, pois é imprescindível, do ponto de vista metodológico, para os futuros encaminhamentos da pesquisa, a busca para encontrar uma possível resposta à problemática de formação relativo ao SND.

Nesse sentido, sob os pressupostos da TAD, uma resposta ao questionamento $\mathbf{Q}$ demanda metodologicamente que os professores em formação inicial sejam encaminhados ao encontro de situações, não planejadas a priori, que os levem a manifestar gestos, como narrativas e ações, que permitam observar os professores e, com segurança, validar ou não a presença da naturalização do SND nesse contexto de práticas. A metodologia que considera essas características foi proposta por Chevallard (2009) sob a denominação de percurso de estudos e pesquisas, ou simplesmente PEP, e que nos ocupamos a seguir.

\section{Recursos teóricos e metodológicos}

A metodologia do PEP assume que nenhuma condição, como a naturalização, por exemplo, está assegurada a priori como existente, tampouco como uma condição restritiva. Essas condições são incertas e somente podem ser observadas em situações que as fazem emergir durante o seu desenvolvimento.

As situações são encaminhadas em meio a questionamentos determinados que derivam de questionamentos indeterminados sobre um dado conhecimento, teórico ou prático, em contexto concreto que busca o desenvolvimento de respostas, ditas parciais para atender as intenções e interesses de seus agentes, nesse caso, os professores e os pesquisadores.

Especificamente, nesta investigação, o PEP se desenvolveu a partir de um sistema didático denotado por $\mathbf{S}\left(\mathbf{F I}, \mathbf{D}, \mathcal{Q}_{1}\right)$ que foi instituído pela comunidade de estudo composta de um conjunto FI de vinte e cinco professores em formação inicial, todos orientados pelo pesquisador $\mathbf{D}$, para produzir uma resposta $R^{\boldsymbol{v}}$ à questão $\mathcal{Q}_{1}$ e $\mathcal{Q}_{1}$ : Qual a provável aparência física desse povo? de interesse dos professores em formação inicial. Esquematicamente, assim representado [S (FI, D, $\left.\mathcal{Q}_{1}\right) \rightarrow \mathbf{R}^{\mathbf{v}}$ ].

O orientador e os professores em formação inicial pertencem a um instituto acadêmico dedicado a formação, em nível de graduação, de professores para o ensino de ciências e matemática para as series iniciais e, em nível de pósgraduação de mestres e doutores na área de Educação de Ciências e Matemática.

É necessário destacar que o PEP aqui considerado é parte de um PEP principal, mais abrangente, que articula um complexo de sistemas didáticos instituídos pelo sistema didático principal $\mathbf{S}\left(\mathbf{D}, \mathbf{O}, \mathbf{Q}_{\mathbf{T}}\right)$, composto pelo Doutorando $\mathbf{D}$ e seu orientador $\mathbf{O}$ para construir uma resposta $\mathbf{R}^{\mathbf{T}}$ à questão de tese $\mathbf{Q}_{\mathbf{T}}$. Esse $P E P$ principal demandou a criação de um sistema didático $\mathbf{S}(\mathbf{D}, \mathbf{O}, \mathbf{Q})$, relativo a esta investigação, para encontrar uma reposta $\mathbf{R}_{\mathbf{Q}}$, esquematicamente, grosso modo, a pesquisa completa assim desenvolvida:

$$
\left[S\left(D, O, Q_{T}\right) \rightarrow S(D, O, Q) \rightarrow S\left(F I, D, Q_{1}\right) \rightarrow R^{\vee} \rightarrow R_{Q} \rightarrow \ldots \rightarrow . R^{\top}\right] \text {. }
$$


Assim, aqui referimos apenas parte do PEP principal que é o relativo a esta investigação, no caso, o desenvolvido para responder a questão $\mathbf{Q}$.

Em geral, durante o desenvolvimento da construção cronológica e epistemológica de um conhecimento sobre o SND, proporcionado pelo PEP, uma resposta poderá se mostrar satisfatória para atender a intencionalidade didática buscada, mas não perderá nunca seu status de provisória, uma vez que o incerto desenvolvimento do PEP deve levar a novos questionamentos que podem levar ao encontro de novas condições que podem alterar a última resposta encontrada, resultando em uma nova resposta.

Os agentes do PEP assumem papeis distintos em seu desenvolvimento. $O$ pesquisador assume o papel de ajuda ao estudo, consistindo basicamente em delimitar a profundidade de estudo de uma obra, por exemplo, bem como o de levar os professores em formação a assumir o protagonismo das ações. Enfim, o pesquisador deve resistir a habitus professoral de se colocar como detentor de respostas às questões formuladas. Os professores em formação por outro lado, devem ser os protagonistas das ações, formulando questões sobre os objetos que emergem para eles durante a investigação e buscando construir respostas a essas questões.

De modo geral, ambos devem objetivar uma "epistemologia funcional dos conhecimentos" (BOSCH; GASCÓN, 2010, p. 86, tradução nossa) que conceba os conhecimentos disciplinares, o que inclui a matemática, e os não disciplinares, como os conhecimentos práticos e/ou tradicionais para construir respostas para as questões problemáticas postas.

Os agentes, em todo o percurso, e em particular o diretor de estudo, devem observar dois princípios: o da ignorância metódica, considera-se sempre que não se conhece, ainda que eventualmente, os elementos de respostas recorrentes na instituição - a escola, por exemplo - para as questões que fazem parte da pesquisa; e o da dúvida metódica, que assume que qualquer afirmação que emerja em um sistema didático sobre as questões e sobre a pesquisa deve ser considerada fundamentalmente como conjectural, ou seja, "não se deve acreditar ou rejeitar a priori, permitindo que seja trabalhada posteriormente a sua veracidade, principalmente quando não é uma afirmação muito conhecida por parte expressiva dos estudantes da pesquisa" (CHEVALLARD, 2009, p. 14, tradução nossa).

Esse contrato didático, que não é usual em salas de aulas, inclusive no ensino superior, provê condições para o desenvolvimento de um estudo investigativo capaz de produzir o encontro de situações questionadoras sobre os sistemas de numeração, cujas respostas ratificadas por essa comunidade, podem se constituir em elementos de uma resposta para uma questão $\mathbf{Q}$ e, em particular, em uma trajetória de formação docente considerando as possíveis mudanças de relações dos professores em formação inicial com o SND que podem ocorrer nesse processo.

Sob a compreensão da TAD, a matemática é descrita em termos de situações e enfaticamente consiste em como lidamos com os problemas em um sentido amplo. Nesse pensar, a matemática é interpretada como uma atividade humana situada, ou seja, realizada no interior de instituições concretas em situações com uma "razão de ser" e, portanto, dotadas de racionalidades que thes dão um significado. É preciso levar em conta que as práticas são realizadas sob condições institucionais, inclusive restritivas, que podem influenciar o nível de complexidade de articulações 
dos conhecimentos necessários, teóricos e ou práticos, para a reconstrução de um dado conhecimento matemático da escola. Não é por acaso que nesse âmbito teórico seja de interesse responder questão do tipo "Como as situações podem ser concebidas e seu desenvolvimento geridos em uma dada instituição de ensino?" (CHEVALLARD; BOSCH; GASCÓN, 2001, p. 3, tradução nossa).

Assim, a direção de estudo encaminhou uma condição pedagógica para realização do PEP, a de considerar as práticas com matemática sobre o SND que vivem nas instituições docentes dos anos iniciais das escolas de ensino fundamental, entre elas, as de quantificação de grandezas físicas a partir de manipulação de unidades dessas grandezas, tendo em conta o interesse da formação docente frente ao SND considerando a articulação matemático-pedagógica de construção epistemológica do SND, e, especificamente, de levar os professores ao encontro do conhecimento teórico, enquanto modelo matemático, a partir do saber-fazer das práticas manipulativas.

Essa compreensão vai ao encontro de um dos interesses de pesquisa defendidos pela TAD, que consiste em delimitar vantajosamente o retorno alcançado das organizações de ensino, considerando certas economias retrospectivas, a partir da gênese sócio-histórica do conhecimento designado para ser ensinado. Isso se traduz, no caso concreto do SND, "em considerar que o conhecimento prático antecede o conhecimento teórico, embora classicamente os livros da instituição matemática apresentem o conhecimento prático como simples aplicação do conhecimento teórico". (CHEVALLARD, 1999, p. 225, tradução nossa).

Nesse seguimento, o conhecimento prático do processo de quantificação poderia ganhar destaque se encaminhado como fundamento do SND, pois funciona sob uma lógica prática que ainda está presente na humanidade e que lhe dá razão ou sentido. Essa lógica prática ainda provê condições para o desenvolvimento de diversas práticas sociais pertencentes a diferentes atividades humanas, por exemplo, a da concepção e de desenvolvimento de automações de processos que governam inúmeras práticas sociais em diferentes sociedades de nosso planeta, principalmente por meio de computadores. Isso certamente está para além da ideia de numerais decimais como uma inquestionável sequência de "números" com sucessor/antecessor pela adição ou subtração de um.

Não menos importante, o processo de quantificação não exige conhecimentos teóricos matemáticos complexos, permitindo o uso, até por crianças, desse processo na quantificação de grandezas concretas, alcançável pelo uso de materiais manipulativos existente nas escolas.

Assim, o PEP foi encaminhado por meio de uma situação em contexto tendo em vista a recomendação de Ripoll, Rangel e Giraldo (2016) sobre o trabalho dos professores com sistemas numéricos não decimais, pois encaminha e explicita a compreensão dos sistemas numéricos decimais, mas levando em conta o acesso e validação por eles de práticas docentes sobre o SND.

\section{Empiria do PEP e análise de dados}

A situação criada para a instituição do PEP foi proposta considerando a necessidade de observância dos princípios da dúvida e da ignorância metódica. Para isso, foi tomado um contexto não rotineiro que permitisse o enfrentamento de 
questionamentos de um sistema de numeração não usual, ainda que hipotético, tendo em vista que o rotineiro reduziria o PEP a uma simples tarefa rotineira que é dotada de uma resposta pronta, como obra dos habitus ${ }^{2}$ associados a uma situação rotineira, no sentido dado por Bourdieu (2004), e, com isso, não atenderia ao propósito dessa metodologia de pesquisa para validar ou não a hipótese de naturalização. Especificamente a situação foi assim apresentada:

Pertenço a um povo parecido com os humanos. Possuo I boca, V olhos e Z membros, como eles. Mas me diferencio por possuir apenas A, ou seja, Z menos I, dedos em cada um desses membros, além de não possuir pelos, ou seja, O pelos em todo o corpo.

Em meu planeta nós cultivamos grãos e tubérculos como os terráqueos. Em particular, em nosso último ano solar AIOOO, que corresponde numericamente ao ano solar cristão da terra de 2000 , obtivemos a seguinte produção:

\begin{tabular}{|c|c|} 
Quadro 1- Representação de grãos ou tubérculos \\
\hline PRODUTOS & PRODUÇÃO \\
\hline Feijão & AZOIO \\
\hline Arroz & ZVAll \\
\hline Mandioca & ZZAAV \\
\hline \multicolumn{2}{|c|}{ Fonte: Próprios autores }
\end{tabular}

Em meu planeta usamos apenas os registros de representação $\mathrm{V}, \mathrm{A}, \mathrm{Z}$, I e O para representar as quantidades.

A partir das informações fornecidas na situação descrita no texto, responda a seguinte questão $\mathcal{Q}_{1}$ : Qual a provável aparência física desse povo?

A dinâmica do desenvolvimento do PEP instituído pelo sistema didático S (FI, D, $\left.\mathbf{Q}_{1}\right)$ consistiu de duas fases bem definidas e estreitamente dependentes entre si:

1 - Foram recorrentes o uso de quatro sistemas didáticos auxiliares $\mathbf{S}_{\mathbf{k}}\left(\mathbf{F} \mathbf{I}_{\mathbf{k}}, \mathbf{Q}_{\mathbf{1}}\right)$ $(k=1,2,3,4)$, instituídos por quatro grupos de de professores em formação inicial oriundos da partição de FI. Cada sistema didático auxiliar desenvolveu as cinco tarefas de uma verdadeira pesquisa (CHEVALLARD, 2013a) que considera possíveis respostas parciais prontas $\mathrm{R}^{\#}$ e existentes na instituição docente; analisálas; avaliá-las; e desenvolver uma resposta própria $\mathrm{R}_{\mathrm{k}}{ }^{*}$.

2 - Cada sistema auxiliar $\mathbf{S}_{\mathbf{k}}\left(\mathbf{F} \mathbf{I}_{\mathbf{k}}, \mathbf{Q}_{\mathbf{1}}\right)$ difundiu e defendeu suas respostas próprias $\mathrm{R}^{*}{ }_{k}$ mediante ao julgamento de $\mathbf{S}_{1}\left(\mathbf{F I}, \mathbf{D}, \mathcal{Q}_{1}\right)$.

A primeira fase foi desenvolvida em espaço extraclasse sem participação de D e anterior a segunda fase desenvolvida por $\mathbf{S}_{1}\left(\mathbf{F I}, \mathbf{D}, \mathcal{Q}_{1}\right)$.

As dialéticas intragrupos (fase 1) e intergrupos (fase 2) produziram um complexo de articulações e integrações de conhecimentos de diferentes naturezas envolvendo uma sequência de questionamentos e respostas que produziram uma trajetória,

\footnotetext{
${ }^{2}$ O habitus como social inscrito no corpo, no indivíduo biológico, permite produzir uma infinidade de atos de jogo que estão inscritos no jogo em estado de possibilidades e de exigências objetivas; as coações e exigências do jogo, ainda que não estejam reunidas num código de regras, impõem-se àqueles e somente àqueles que, por terem o sentido do jogo, isto é, o senso da necessidade imanente do jogo, estão preparados para percebêlas e realizá-las. (BOURDIEU, 2004, p.82)
} 
entre outras possíveis e presentes no PEP, que levam ao encontro de uma resposta $\mathrm{R}_{1}{ }^{\boldsymbol{}}$ é esquematicamente apresentada na Figura 1.

Figura 1- Percurso das dialéticas entre os grupos

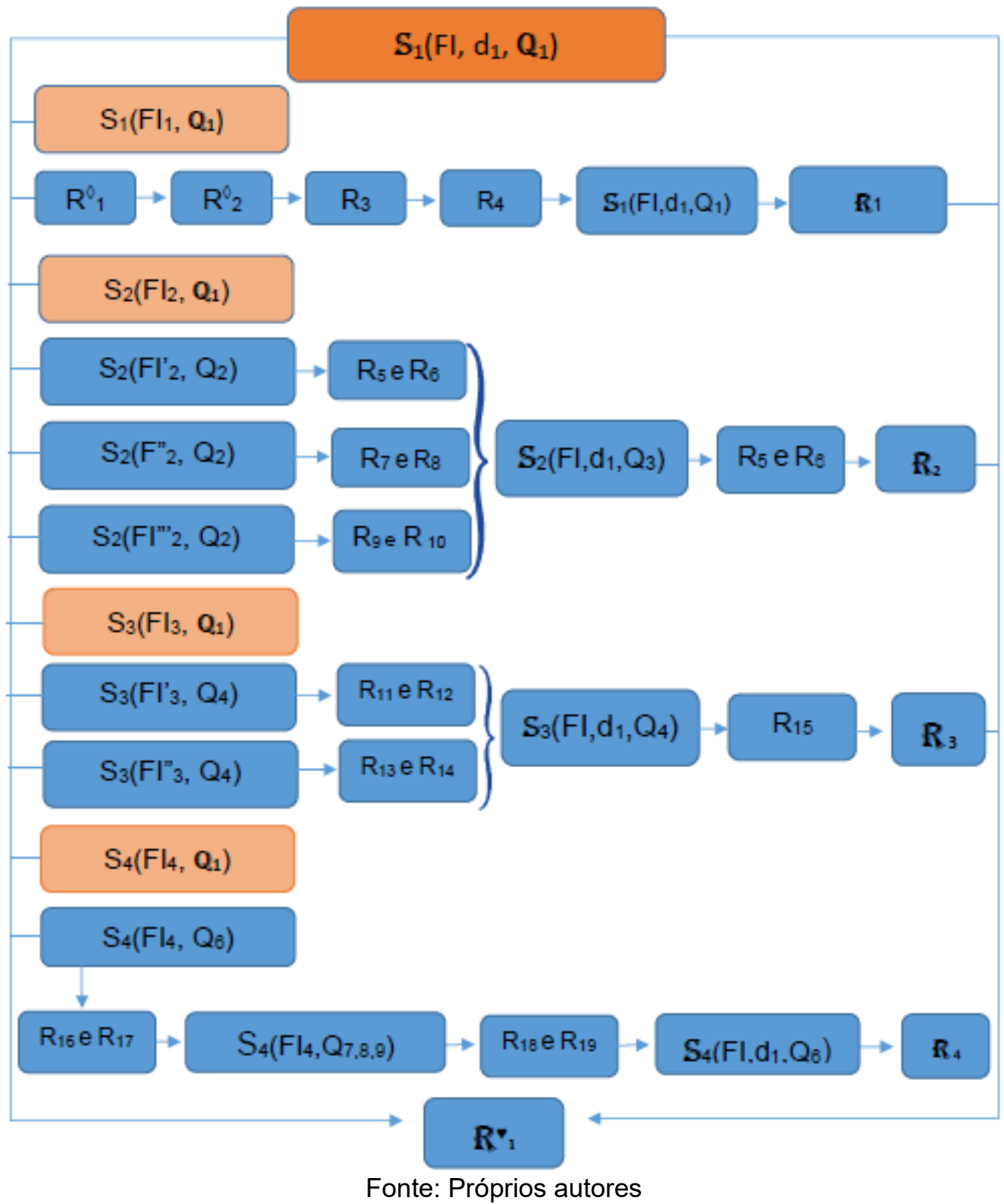

Legenda:

Q1: Qual seria a provável aparência física desse povo?

Q1:Quais algarismos hindu-arábicos correspondem a cada letra?

Q2: Quais totalidades de quantidades são representadas pelas letras $(\mathrm{O}, \mathrm{I}, \mathrm{V}, \mathrm{A}, \mathrm{Z})$ no sistema de numeração dos Et's?

Q3: Animais são um povo?

Q4: Quais algarismos arábicos correspondem a cada quantidade?

Q5: Quantos membros o corpo humano é formado?

Q6: Quais os algarismos hindu-arábicos correspondem cada letra? 


\section{Q7: O que é ano solar cristão?}

Q8: Então isso é sistema binário?

Q9: A representação que nos foi apresentada aqui são os mesmos da Terra?

Q10: Precisamos pesquisar o que são números professora, que não são letras, de onde surgiu?

Q11: Qual relação entre as letras e os símbolos?

Q12: Que relação o povo romano tem a ver com a representação dos Et's?

Especificamente, os questionamentos que emergiram nos diferentes sistemas didáticos auxiliares que compuseram o sistema didático principal $\mathbf{S}_{1}\left(\mathrm{FI}, \mathrm{D}, \mathcal{Q}_{1}\right)$, encaminharam os seguintes elementos da resposta $\mathrm{R}_{1}{ }^{\mathrm{v}}$ :

1) A interpretação das letras como algarismos hindu-arábicos: $O=0 ; I=1 ; V=2 ; A$ $=3 ; Z=4$;

2) Figura de um humanoide, como o da Figura 2

Figura 2 - Representação do Et

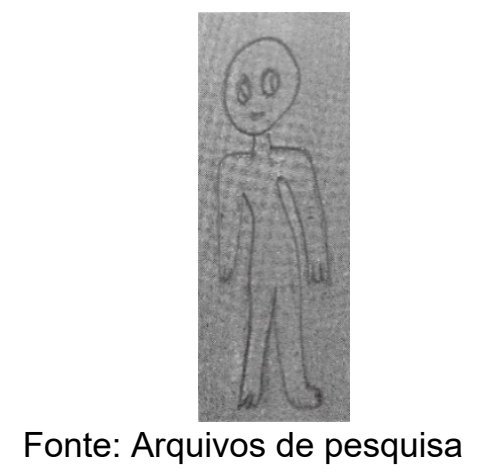

As totalidades físicas identificadas por FI na constituição corporal dos Et's, com numerais hindu-arábicos, revelam que eles conseguem fazer a identificação das unidades de grandezas físicas com a unidade numeral e contam umas como se fossem as outras, evidenciando o conhecimento de totalidades finitas de quantidades físicas inquestionáveis identificadas com numerais de 1 até 9 , inclusive com a de ausência de unidades, no caso, representada pelo numeral zero.

Os conhecimentos inquestionáveis, aos quais nos referimos, são por nós compreendidos no sentido dado por Chevallard (2004) sobre conhecimentos que são aprendidos sem serem intencionalmente programados para serem ensinados, mas incorporados pelo uso em práticas sociais, inclusive da escola e, portanto, constituem conhecimentos naturalizados e, não raros, banalizados, por conseguinte, destituído de complexidades para o ensino.

Essa compreensão sobre a naturalização do SND no seio das práticas dos professores em formação inicial e participantes do PEP, é ratificada no seguinte extrato das dialéticas desenvolvidas no PEP, em particular durante a apresentação do último sistema auxiliar $\mathbf{S}_{\mathbf{4}}\left(\mathbf{F l}_{\mathbf{4}}, \mathbf{Q}_{1}\right)$ para julgamento do sistema $\mathbf{S}\left(\mathbf{F I}, \mathbf{D}, \mathbf{Q}_{1}\right)$ que encaminha a compreensão de que o SND não é percebido ou não conhecido como um SNP pelos professores em formação inicial.

4


No fragmento das dialéticas a seguir, a expressão $\mathbf{G}_{\mathbf{k}}$ denota a fala do professor em formação inicial como fala do grupo $\mathrm{k}(\mathrm{k}=1,2,3,4)$ a que pertence.

G4: Vejam só, 4 não necessariamente é 4 isso é um código... do que é o 4 ...

G3: Q8: Então isso é sistema binário?

G4: Não, não. É outro

D: Então explica pra eles por que não é binário

G4: Porque binário são só dois 0 e 1, então por isso, não é? É um sistema com 4 possibilidades, não é isso?

$\mathrm{G}_{1}$ : Cinco, cinco possiblidades

G4: R18: É um sistema quinário!

$\mathrm{G}_{1}$ : Muito bom, isso aí!

D: Pra gente encerrar, essa seria então a representação da produção desse povo, né isso? sim ou não?

Fi's: Sim!!!

G1: É bom dá esse destaque!

D: Q9: Então está representação que nos foi apresentada aqui são os mesmos da Terra?

Fi's: Não!!

D: Por que? O que os diferenciam?

$\mathrm{G}_{4}$ : R19: Um é sistema quinário, o outro é decimal

D: Quinário por que?

$\mathrm{G}_{2}$ : Porque tem somente 5 representações

D: Então o que eles faziam com essas representações?

$\mathrm{G}_{3}$ : Eles combinavam ordem

D: E o que é essa organização de ordens?

$\mathrm{G}_{1}$ : Acho que é o tempo dessas produções

$\mathrm{G}_{1}$ : Faziam a construção de outros números, pela subtração

$\mathrm{D}$ : O que é quantidade?

$\mathrm{G}_{1}$ : Tipo assim ... a soma nesse caso envolveria as operações nós temos uma quantidade de numerações, e a partir delas se faz a construção de maiores quantidades.

Destas falas ratificamos a compreensão sobre o SND não ser percebido ou não ser conhecido como um SNP pelos professores em formação inicial, pois em nenhuma dialética é mencionado esse tipo de sistema, mas tão somente sistema posicionais particulares, como sistemas isolados, portanto como sistemas que não compartilham de uma estrutura comum. Isso é evidenciado, principalmente quando os professores relacionam os numerais dos Et's com numerais de diferentes sistemas de numeração, como dos romanos, decimal, híbridos de decimal e romanos, para concluir, como evidenciam as falas, como um sistema do tipo do

(2.


sistema de numeração binário, chamado por eles de sistema de numeração quinaria (SNQ). Entretanto, não encaminham relações que revele o SND como um SNP, pois não realizam relações entre os sistemas posicionais conhecidos por eles, como o binário, com o sistema decimal, inclusive que permitisse "traduzir" o registro dos Et's em um registro numérico decimal.

\section{Algumas considerações e encaminhamentos futuros}

Em síntese, a situação em contexto permitiu o desenvolvimento de um PEP por meio de mobilização de conhecimentos em ações, em situações de quantificações com uso de registros escritos não usuais. O estranhamento à situação colaborou para a emersão de questionamentos e contribui para observância dos princípios da ignorância e da dúvida metódica.

No desenvolvimento dos estudos e investigações, paulatinamente, ficou notório para nós a hipótese encaminhada pelos teóricos aqui considerados, como: Terigi e Wolman (2007), Ripoll, Rangel e Giraldo (2016) e Itzcovich (2008), sobre o SND ser um conhecimento naturalizado na sociedade e, em particular, nas práticas escolares, em que se inserem os professores em formação, assim se confirmou como verdadeira.

Essa nossa conclusão se depreende do fato de que os professores em formação quando em frente a diferentes práticas de numeração não fazem nenhuma relação entre os sistemas posicionais com o sistema decimal. Este sistema foi parcialmente movimentado pelos professores em formação.

A empiria do PEP evidenciou o potencial da situação criada em um contexto estranho aos professores em formação como provedora de condições para a criação do ambiente crítico onde há argumentações necessárias para o desenvolvimento de atitudes de protagonismo questionador pelos professores sobre o SND. Essa atitude se evidencia, sobretudo, com o encaminhamento do PEP para produção de nova resposta, denominada de sistema quinário. Isso proporciona a expansão das compreensões que permitiriam a leitura do quadro de produção agrícola dos Et's. Isso exigirá, sob as condições pedagógicas postas, encontrar objetivamente a estrutura do sistema de numeração dos Et's. Talvez isso possa encaminhar a desnaturalização do SND. Esse é nosso objetivo no seguimento dessa pesquisa.

É importante destacar o caráter pluridisciplinar da metodologia do PEP quando, de modo explícito, mobiliza o conhecimento de diferentes naturezas, inclusive culturais, constituindo-se pelo modo de questionar o mundo (CHEVALLARD, 2004, 2009, 2013). Ele pode fazer uma efetiva mudança de rota no ensino tradicional, posto que o ensino e a aprendizagem têm sido centrados nos professores.

O convívio dos professores proporcionado no desenvolvimento do PEP permitiu o questionamento dos conhecimentos matemáticos em relação a outros conhecimentos que vivem na escola e na sociedade, o que os levou ao encontro de novos olhares sobre os elementos dos sistemas de numeração, inclusive sobre as práticas de ensino por eles já vivenciadas.

Considerando que PEP levou os professores em formação inicial ao encontro de novos olhares e de novos conhecimentos sobre os sistemas de numeração, 
inclusive com a proposição do sistema já mencionado e titulado de sistema de numeração quinário (SNQ), podemos assegurar que o percurso de estudo se constituiu em uma trajetória de formação docente sobre sistemas de numeração.

Essa trajetória não é única, pois cada professor em formação realizou dinâmicas cognitivas pessoais que podem diferir em muito da trajetória destacada pelo pesquisador, mesmo que todos busquem uma resposta para uma mesma questão. Por outro lado, todas devem diferir da trajetória criada pelo pesquisador, considerando que suas dinâmicas cognitivas atentem para outra questão a ser respondida, no caso, a questão da presente pesquisa. Reiteramos que este trabalho é um recorte de uma pesquisa de doutoramento em andamento e que os resultados apresentados estão passiveis de mudança, diante de um todo, e a resposta apresentada é prévia e parcial.

\section{Referências}

BATHELT, R. E. A Psicologia do Número, Revista: Educação, Santa Maria - RS, ano 2000 , Vol. 25, n. 1, p. 97-112.

BOSCH, M.; GASCÓN, J. Las prácticas docentes del profesor de matemáticas. XlèmeÉcoled'Été de Didactique des Mathématiques, de 2001.

BOSCH, M.; GASCÓN, J. Fundamentación antropológica de las organizaciones didácticas: de los "talleres de prácticas matemáticas" a los "recorridos de estudio e investigación". Diffuser les mathématiques (et les autres savoirs) comme outils de connaissance et d'action, p.49-85,2010. Disponível em: http://www.atd.tad.org/wapontent/upload/2012/05/marianaJosepCITAD-II-2010.pdf. 2010.

BOURDIEU, P. Coisas ditas. Tradução Cássia R. da Silveira e Denise Moreno Pegorin; Ed.Brasiliense, 2004.

BOSCH, M, CHEVALLARD, Y, GARCÍA, F, MONAGHAN, J. Working with the Anthropological Theory of the Didactic in Mathematics Education. A Comprehensive Casebook, 2019.

BROUSSEAU, G. Théorie des situations didactiques: Didactique des mathématiques 1970-1990 (N. Balacheff, M. Cooper, R. Sutherland and V. Warfield, Eds.). Grenoble: La Pensée Sauvage, Éditions 1998.

CARVALHO, M. Pedagogia e os Conteúdos Matemáticos: a Formação do Professor dos Anos Iniciais e Educação Infantil, Anais do IX ENEM, Belo Horizonte-MG, 2007.

CENCI, D.; BECKER, M. L. R.; MACKEDANZ, L. F. Produções Acadêmicas sobre o ensino do sistema de numeração decimal: O Estado da Arte. Revista de Divulgação. Científica em Ciências Exatas e Tecnológicas - PORANDU. Rio Grande do Sul, Vol. 1, n. 1, p.29-41, 2015.

CHEVALLARD, Y. La transposition didactique. Du savoir savant au savoir eneigné, La pensée Sauvage. Grenoble, 1985

CHEVALLARD, Y. El análisis de las prácticas docentes em la teoria antropológica de lo didáctico. Recherches em Didactique des Mathématiques, Vol 19, $\mathrm{n}^{\circ} 2, \mathrm{pp}$. 221-266. Ano 1999.

4


CHEVALLARD, Y. La place des mathématiques vivantes dans l'éducation secondaire: transposition didactique des mathématiques et nouvelle épistémologie scolaire. 3e Université d'été Animath, Saint-Flour (Cantal), France 22 al 27 août, 2004.

CHEVALLARD, Y. À propos des PER. In: Journal du Seminaire TAD/IDD - 1; pp. 723, 2009 Disponível em: http://yves.chevallard.free.fr/spip/spip//MG/pdf/journal-tadidd-2009-20010-1.pdf Acessado em 27 mar. 2019.

CHEVALLARD, Y. La matemática en la escuela: Por una revolución epistemológica y didáctica, Buenos Aires. Libros del Zorzal, 2013a

CHEVALLARD, Y. Enseñar Matemáticas en la Sociedad de Mañana: Alegato a Favor de un Contraparadigma Emergente, Redimat. Journal of Research in Mathematics Education, 2 (2), p.161 -182. 2013.

CHEVALLARD, Y.; BOSCH, M.; GASCÓN, J. Estudar matemáticas: o elo perdido entre o ensino e a aprendizagem. Tradução: Daisy Vaz de Moraes. Porto Alegre: Artmed. 2001.

GARCIA, M. F. Os Saberes de Professores de Educação Infantil em Relação à Construção Numérica: Formação de Professores em um Grupo Cooperativo. 2006. 251 folhas. Dissertação de Mestrado (Dissertação em Educação Matemática) Pontifícia Universidade Católica de São Paulo, Programa de Pós-Graduação Profissional em Ensino de Matemática, São Paulo, SP, Brasil, 2006.

IFRAH, G. Os Números. História de uma grande invenção. São Paulo, Editora Globo, 1985, Ed. $2^{\mathrm{a}}$.

ITZCOVICH, H. (Coord). La matemática escolar: las prácticas de enseñanza en el aula. Buenos Aires, Editora Aique Educación, 2008. Ed. 1ª

KLEIN, F. Matemática de um Ponto de Vista Superior. Volume I. Parte I Aritmética. SPM, Lisboa, 2009.

KLEIN, F. Matemática de um Ponto de Vista Superior. Volume I. Parte II Algebra. SPM, Lisboa, 2010.

KLEIN, F. Matemática de um Ponto de Vista Superior. Volume I. Parte III Análise. SPM, Lisboa, 2011.

RIPOLL, C. RANGEL L., GIRALDO V. Livro do professor de Matemática na Educação Básica: Números naturais. Rio de janeiro. Editora. SBM, 2016.

SADOVSKY, P. La enseñanza de la matemática en la formación docente para la escuela primaria. Edição $1^{a}$. Buenos Aires: Ministerio de Educación de la Nación, v. 2, 2010.

SCHOENFELD, A. H. Models of the Teaching Process, Journal of Mathematical Behavior, V.18(3), p. 243-261, 2000.

SHULMAN, L. Those Who Understand: Knowledge Growth in Teaching. Educational Researcher, v. 15, p. 4-14, 1986.

TERIGI, F e WOLMAN S. Sistema de numeración: consideraciones acerca de su enseñanza. Revista iberoamericana de educación. Buenos Aires, n 43, p. 59-83, 01 janeiro de 2007. Disponível em: https://rieoei.org/historico/documentos/rie43a03.pdf, Acesso em 06 agosto 2019.

4


Recebido: 04/03/20

Aprovado: 28/05/20

Como citar: FERREIRA, R. S. R.; GUERRA, R. B. Formação inicial de professores que ensinam matemática e o sistema de numeração decimal. Revista de Estudos e Pesquisa sobre Ensino

Tecnológico (EDUCITEC), v. 6, Edição Especial, e118720, 2020.

Direito autoral: Este artigo está licenciado sob os termos da Licença Creative CommonsAtribuição 4.0 Internacional.

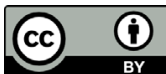

